\title{
Effect of Cadmium on the Level of Isoprenoid-Derived Phytohormones in Duckweed Wolffia arrhiza
}

\author{
${\text { Magdalena } \text { Chmur }^{1} \text { (D) Andrzej Bajguz }}^{1}$ (D) $\cdot$ Alicja Piotrowska-Niczyporuk $^{1}$ (D)
}

Received: 26 February 2020 / Accepted: 20 May 2020 / Published online: 28 May 2020

(c) The Author(s) 2020

\begin{abstract}
Wolffia arrhiza (L.) Horkel ex Wimm. is an aquatic plant belonging to the Lemnaceae family. It does not have leaves, stems, and roots, flowers rarely occur, while body size can reach $1 \mathrm{~mm}$ of width and $1.3 \mathrm{~mm}$ of length. The present study demonstrates the endogenous level of isoprenoid-derived phytohormones and their changes under the influence of different cadmium $(\mathrm{Cd})$ concentrations $(0.1,1,10$, and $100 \mu \mathrm{M})$. A liquid chromatography quadrupole-time-of-flight mass spectrometry analysis indicated the presence of abscisic acid, eight brassinosteroids (6-deoxocastasterone, 6-deoxotyphasterol, cathasterone, typhasterol, castasterone, 24-epicastasterone, brassinolide, and 28-homobrassinolide), seven free bases of cytokinins [trans-zeatin $(t Z)$, cis-zeatin $(c Z)$, dihydrozeatin (DHZ), $N^{6}$-isopentenyladenine, $N^{6}$-isopentenyladenosine, ortho-topolin, and $m e t a$-topolin], eight conjugates of cytokinins ( $t Z$ riboside, $t Z$-9-glucoside, $t Z$-7-glucoside, $t Z$ - $O$-glucoside riboside, $c Z$-9-glucoside, DHZ riboside, DHZ- $O$-glucoside, and $N^{6}$-isopentenyladenosine-7-glucoside) and gibberellic acid $\left(\mathrm{GA}_{3}\right)$ in this duckweed. The level of phytohormones in plants treated with $\mathrm{Cd}$ has changed, e.g., the ABA level increased while $\mathrm{GA}_{3}$ decreased. Whereas the amount of BRs and CKs was different in Cd dose-dependent manner. Besides, it is worth noting that the distribution of 25 various phytohormones in the Wolffia arrhiza is reported for the first time.
\end{abstract}

Keywords Abscisic acid · Brassinosteroids · Cadmium stress · Cytokinins · Gibberellic acid · Occurrence

$\begin{array}{ll}\text { Abbreviations } \\ \text { EBL } & \text { 24-Epibrassinolide } \\ \text { ECS } & \text { 24-Epicastasterone } \\ \text { HBL } & \text { 28-Homobrassinolide } \\ \text { 6dCS } & \text { 6-Deoxocastasterone } \\ \text { 6dTY } & \text { 6-Deoxytyphasterol } \\ \text { ABA } & \text { Abscisic acid } \\ \text { BL } & \text { Brassinolide } \\ \text { BR } & \text { Brassinosteroid } \\ \text { CS } & \text { Castasterone } \\ \text { CT } & \text { Cathasterone } \\ \text { CK } & \text { Cytokinin } \\ c Z & \text { cis-Zeatin } \\ \text { DHZ } & \text { Dihydrozeatin }\end{array}$

Electronic supplementary material The online version of this article (https://doi.org/10.1007/s00344-020-10154-9) contains supplementary material, which is available to authorized users.

Andrzej Bajguz

abajguz@uwb.edu.pl

1 Faculty of Biology, University of Bialystok, Konstantego Ciolkowskiego 1J, 15-245 Bialystok, Poland

$\begin{array}{ll}\text { DHZOG } & \text { Dihydrozeatin- } O \text {-glucoside } \\ \text { DHZR } & \text { Dihydrozeatin riboside } \\ \text { GA } & \text { Gibberellin } \\ \text { GA }_{3} & \text { Gibberellin } \mathrm{A}_{3} \\ \text { iP } & N^{6} \text {-Isopentenyladenine } \\ \text { iPR } & N^{6} \text {-Isopentenyladenosine } \\ \text { iPR7G } & N^{6} \text {-Isopentenyladenosine-7-glucoside } \\ t Z & \text { trans-Zeatin } \\ t Z 7 G & \text { trans-Zeatin-7-glucoside } \\ t \text { Z9G } & \text { trans-Zeatin-9-glucoside } \\ t \text { ZROG } & \text { trans-Zeatin- } O \text {-glucoside riboside } \\ t \text { ZR } & \text { trans-Zeatin-riboside } \\ \text { TY } & \text { Typhasterol }\end{array}$

\section{Introduction}

The Lemnaceae (duckweed) comprises an aquatic monocotyledon family, including only 37 species arranging within five genera and in majority widely distributing in the world. They are the smallest angiosperms, some of which may attain a width of only $0.3 \mathrm{~mm}$ at maturity (Les et al. 2002; Sree et al. 2016). Among Lemnaceae and other higher 
plants, Wolffia arrhiza (L.) Horkel ex Wimm. has significantly reduced organs, it does not have a stem, leaves, and root system. Body size can reach $1 \mathrm{~mm}$ of width and $1.3 \mathrm{~mm}$ of length, while flowering occurs extremely rarely (Schmitz and Kelm 2017; Khvatkov et al. 2018). Despite simplified body structure, these plants play crucial roles in the protection of the aquatic environment. In organic-rich water, they change the feeding from photoautotrophic into either mixotrophic or heterotrophic. Furthermore, duckweeds can bioaccumulate heavy metals and xenobiotics from polluted waters (Les et al. 1997; Vermaat and Hanif 1998; Samardakiewicz and Woźny 2000; Piotrowska et al. 2010; Soda et al. 2013). Duckweeds are applicable in aquaculture as food for waterfowl and fish. The simplified morphology of the plant enables it to be a good model for laboratory studies (Skillicorn et al. 1993; Piotrowska and Bajguz 2012).

Abscisic acid (ABA), brassinosteroids (BRs), cytokinins (CKs), and gibberellins (GAs) are classes of naturally occurring isoprenoid-derived phytohormones, which regulate plant growth and development, ranging from differentiation, through the transport of nutrients to responses on abiotic and biotic stresses (Weyers and Paterson 2001; Verma et al. 2016; Ku et al. 2018; Sytar et al. 2019). ABA is an isoprenoid sesquiterpenoid $\left(\mathrm{C}_{15}\right)$ synthesized from carotenoids, in most cases, from xanthophylls. The intracellular level of this compound increases when plants are exposed to biotic and abiotic stresses because ABA is a stress signaling molecule (Cutler and Krochko 1999; Li et al. 2017; Olds et al. 2018). Natural plant CKs are derivatives of adenine purine base with isoprenoid or aromatic side chain that are substituted in $N^{6}$ position. The main forms of CKs are isoprenoid free bases, including trans-zeatin $(t \mathrm{Z})$ and $c i$-zeatin $(c \mathrm{Z})$, which are the most commonly CKs occurring in many higher plants. The most abundant representatives of the aromatic side chain of CKs are para-, meta-, ortho-topolin ( $p$-, $m$-, $o \mathrm{~T})$. CKs also create conjugates, most frequently with ribose or/and glucose, which are attached to the purine ring (Kieber and Schaller 2014; Hönig et al. 2018). GAs are a group of tetracyclic, diterpenoid carboxylic acids; their structure is based on ent-gibberellane $\left(\mathrm{C}_{20}\right)$ or 20-nor-ent-gibberellane $\left(\mathrm{C}_{19}\right)$ carbon skeleton (Hedden and Thomas 2012). Among more than 130 currently known GAs, just a few indicate biological activity, e.g., gibberellic acid $\left(\mathrm{GA}_{3}\right)$. Its chemical structure is a carboxylic acid skeleton with a hydroxyl group in C-3 position and a carboxyl group in C-6 position (Davière and Achard 2013). BRs are comparatively less researched class of phytohormones relative to ABA, CKs, and GAs. So far, more than 70 different BRs have been identified as free molecules or conjugates with fatty acids or glucose, and their differentiation results from the type and position of functional groups within the cyclic A and B rings and the side chain. The base of the chemical structure is the four-ring skeleton of $5 \alpha$-cholestane containing ring $\mathrm{A}$ with hydroxyl group generally at $\mathrm{C}-2$ and $\mathrm{C}-3$ position, then 7-oxalactone, 6-ketone, or non-oxidized ring $\mathrm{B}$ and the side chain with hydroxyl group usually at C-22 and C-23. The most frequent and active types of BRs are brassinolide (BL) and castasterone (CS) (Bajguz and Tretyn 2003; Kanwar et al. 2017; Tarkowska and Strnad 2018; Zullo and Bajguz 2019).

Biological activity of phytohormones varies and depends on biosynthesis rates, cellular localization, transport, and signal perception or exposure to the biotic and abiotic stresses (Cao et al. 2016; Smith et al. 2017; Šimura et al. 2018). In recent decades, a significant increase in environmental contamination by heavy metals was observed, which causes one of the most harmful abiotic stress in the plant. Cadmium (Cd), belonging to the group of heavy metals, has a strongly toxic action for all living organisms, moreover many of aquatic, air, and soil environments are contaminated by this metal (Sytar et al. 2019). After getting inside plant cells, even a low concentration causes a toxic effect manifesting to impair life activities. Cd can form covalent and ionic bonds with biologically essential functional groups, such as sulfhydryl, amine, disulfide, carboxy, and imidazole of micro and macroelements, such as sulfur, hydrogen, oxygen, magnesium, calcium, zinc, iron, copper, and selenium (Bertin and Averbeck 2006). In plants, Cd poisoning negatively affects both physiological and biochemical cellular processes, such as photosynthesis, transpiration, and cellular respiration. In addition, $\mathrm{Cd}$ inhibits cell division and overall organism growth. Moreover, $\mathrm{Cd}$ ions present in plant cells block the activity of antioxidant enzymes located in chloroplasts and mitochondria. This causes oxidative stress and accumulation of reactive oxygen species (Liu et al. 2017).

Plant organs are a rich source of phytohormones that occur in a range of ng-fg per $g$ of fresh weight. Thus, liquid chromatographic separation coupled with mass spectrometry (LC-MS) is the most precise method for the identification and quantification of plant hormones due to high sensitivity, accuracy, and reproducibility. A liquid chromatography quadrupole-time-of-flight mass spectrometry (LC-QToFMS), applied in our studies, is characterized by high mass accuracy and well resolution, so it is an excellent tool for hormones profiling (Pan and Wang 2009; Bai et al. 2010; Pan et al. 2010; Xin et al. 2013; Cao et al. 2016; Chu et al. 2017; Kanwar et al. 2017; Li et al. 2019). Isolation of new or known hormones in plant species remains as a research target of many scientists. Therefore, the present study aimed to determine the endogenous level of ABA, BRs, CKs, and GAs in $W$. arrhiza using the LC-QToF-MS quantitative analysis. Moreover, the effect of different $\mathrm{Cd}$ concentrations (0.1-100 $\mu \mathrm{M}$, increase by one order of magnitude) on phytohormones content was studied. Additionally, the relations between phytohormones, primarily linear, were statistically analyzed. 


\section{Materials and Methods}

\section{Growth Condition}

One gram of the wild type of $W$. arrhiza was grown in sterile, glass vessels containing $200 \mathrm{~mL}$ of $1 / 30$ dilution of Hunter's medium (Hutner 1953) with Cd addition in the range of concentration $0.1-100 \mu \mathrm{M}$ except for control group. The varied solutions of metal were prepared through the diluting of $\mathrm{CdCl}_{2}$ in $1 / 30$ Hutner's medium. The breeding was grown under controlled conditions at $22.0 \pm 0.5^{\circ} \mathrm{C}, 16$-h photoperiod (photon flux of $100 \mu \mathrm{mol} \mathrm{m} \mathrm{m}^{-2} \mathrm{~s}^{-1}$ ), and $65 \pm 1 \%$ humidity for 7 days. Fresh weight was harvested and filtered using a vacuum pump (KNF Laboport, Germany). Then, the sample was homogenized in liquid nitrogen using a mortar and pestle. The resulting powder was used in further analysis.

\section{Chemicals}

The standard of abscisic acid (ABA); eleven standards of BRs: 6-deoxotyphasterol (6dTY), cathasterone (CT), 6-deoxocathasterone (6dCT), typhasterone (TY), castasterone (CS), 6-deoxocastasterone (6dCS), 24-epicastasterone (ECS), brassinolide (BL), 28-norbrassinolide (28-norBL), 24-epibrassinolide (EBL) and 28-homobrassinolide (HBL) twenty-six standards of CKs: transzeatin $(t \mathrm{Z})$, trans-zeatin riboside $(t \mathrm{ZR})$, trans-zeatin9-glucoside $(t Z 9 G)$, trans-zeatin-7-glucoside $(t Z 7 G)$, trans-zeatin- $O$-glucoside ( $t Z O G)$, trans-zeatin riboside- $O$-glucoside $(t Z R O G)$, trans-zeatin-9-glucoside$O$-glucoside( $t Z 9 G O G)$, trans-zeatin-9-glucoside riboside (tZ9GR), cis-zeatin (cZ), cis-zeatin-riboside ( $c \mathrm{ZR})$, cis-zeatin $O$-glucoside (cZOG), cis-zeatin9-glucoside (cZ9G), cis-zeatin- $O$-glucoside-riboside ( $c$ ZROG), dihydrozeatin (DHZ), dihydrozeatin riboside (DHZR), dihydrozeatin-9-glucoside (DHZ9G), dihydrozeatin-7-glucoside $(\mathrm{DHZ7G})$, dihydrozeatin- $O$-glucoside (DHZOG), dihydrozeatin riboside- $O$-glucoside (DHZROG), $N^{6}$-isopentenyladenine (iP), $N^{6}$-isopentenyladenosine (iPR), $N^{6}$-isopentenyladenosine-7-glucoside (iPR7G), paratopolin $(p \mathrm{~T})$, meta-topolin $(m \mathrm{~T})$, ortho-topolin $(o \mathrm{~T})$, 6-benzylaminopurine (6-BAP) and standard of $\mathrm{GA}_{3}$ were purchased from OlChemIm (Olomouc, Czech Republic). Chemicals used to prepare Hunter's medium were purchased from Sigma-Aldrich (St. Louis, USA). 4-(Dimethylamino)phenylboronic acid (DMAPBA), methanol $(\mathrm{MeOH})$, acetonitrile (ACN), water (LC-MS purity), formic acid (FA) and potassium hydroxide $(\mathrm{KOH})$ were purchased from Merck KGaA (Darmstadt, Germany).

\section{Quantification of ABA, Cytokinins, and $\mathrm{GA}_{3}$}

For the measurement of phytohormones, $200 \mathrm{mg}$ of plant powders were placed into the $2 \mathrm{~mL}$ Eppendorf tubes, suspended in $1 \mathrm{~mL}(\mathrm{v} / \mathrm{v}) 50 \% \mathrm{ACN}$ and homogenized in a bead mill (50 Hz, 5 min; TissueLyser LT, Qiagen, Germany) using two $5 \mathrm{~mm}$ tungsten balls. Then, samples were homogenized using the ultrasound processor VCX 130 (max. power $130 \mathrm{~W}$, max. frequency $20 \mathrm{kHz}, 5 \mathrm{~min}$ ) equipped with titanium probe (Sonics \& Materials Inc., USA) and mixed in laboratory shaker $\left(90 \mathrm{rpm}\right.$, dark, $5{ }^{\circ} \mathrm{C}, 30 \mathrm{~min}$; LC-350, PolEko-Aparatura, Poland). Samples were centrifuged $(9000 \times g$, 5 min; MPW-55 Med. Instruments, Poland) and collected in a glass tube. For quantification of $\mathrm{ABA}, \mathrm{CKs}$, and $\mathrm{GA}_{3}$, $\left[{ }^{2} \mathrm{H}_{6}\right](+)$-cis, trans-ABA (50 ng), $\left[{ }^{2} \mathrm{H}_{6}\right] \mathrm{iP}(50 \mathrm{ng}),\left[{ }^{2} \mathrm{H}_{5}\right] \mathrm{tZ}$ (30 ng), $\left[{ }^{2} \mathrm{H}_{5}\right]-t Z O G(30 \mathrm{ng}),\left[{ }^{2} \mathrm{H}_{3}\right]-$ DHZR (30 ng), and $\left[{ }^{2} \mathrm{H}_{2}\right]$ $\mathrm{GA}_{3}(30 \mathrm{ng})$ were added to samples as internal standards.

Prepared extracts were purged using Waters SPE Oasis ${ }^{\circledR}$ HLB cartridge, previously activated and equilibrated using $1 \mathrm{~mL} \mathrm{100 \%} \mathrm{MeOH,} 1 \mathrm{~mL} \mathrm{H}_{2} \mathrm{O}$, and $1 \mathrm{~mL}$ (v/v) 50\% ACN (Šimura et al. 2018). Then, extracts were loaded and collected to the Eppendorf tubes and eluted with $1 \mathrm{~mL} \mathrm{30 \%}$ ACN (v/v). Samples were evaporated to dryness by centrifugal vacuum concentrator (Eppendorf Concentrator Plus, Germany), dissolved in $50 \mu \mathrm{L}$ (v/v) $30 \% \mathrm{ACN}$, and transferred into the insert vials. Detection of analyzed phytohormones was performed using an Agilent 1260 Infinity series HPLC system (Agilent Technologies, USA) contains QToF LC/MS mass spectrometer with Dual AJS ESI source, $10 \mu \mathrm{L}$ of each sample was injected on the Waters XSelect $\mathrm{C}_{18}$ column $(250 \mathrm{~mm} \times 3.0 \mathrm{~mm}, 5 \mu \mathrm{m})$, heated up to $50{ }^{\circ} \mathrm{C}$. Mobile phase A was $0.01 \%$ (v/v) FA in ACN and phase B $0.01 \%$ (v/v) FA in $\mathrm{H}_{2} \mathrm{O}$; flow was $0.5 \mathrm{~mL} \mathrm{~min}^{-1}$. Separation of the above hormones was done in ESI positive mode with the following gradient: $0-8$ min flowing increased linearly from 5 to $30 \%$ A, $8-25 \min 80 \%$ A, 25-28 $\min 100 \%$ A, $28-30 \mathrm{~min} 5 \% \mathrm{~A}$.

\section{Quantification of Brassinosteroids}

Preparation and quantification of BRs were performed as described in detail by Bajguz et al. (2019). Briefly, $200 \mathrm{mg}$ of plant powders were placed into the $2 \mathrm{~mL}$ Eppendorf tubes, suspended in $1 \mathrm{~mL} \mathrm{MeOH}$, and homogenized using two $5 \mathrm{~mm}$ tungsten balls. Then, the homogenates were centrifuged, and the resulting supernatants were transferred to the flat bottom flask and mixed in laboratory shaker $(90 \mathrm{rpm}$, dark, $\left.5{ }^{\circ} \mathrm{C}, 90 \mathrm{~min}\right)$. For quantification of BRs, $\left[{ }^{2} \mathrm{H}_{3}\right] \mathrm{BL}$ (2 ng) and $\left[{ }^{2} \mathrm{H}_{3}\right] \mathrm{CS}(2 \mathrm{ng})$ were added into the mixture, followed by extraction with $\mathrm{MeOH}$ as internal standards. For screening of BRs, no internal standards were added. The samples were purified from pigments and other pollutions using Waters SPE MAX cartridge, which was activated 
and equilibrated with $99.9 \% \mathrm{MeOH}, \mathrm{H}_{2} \mathrm{O}, 1 \mathrm{M} \mathrm{KOH}, 10 \%$ (v/v) $\mathrm{MeOH}$ and 95\% (v/v) $\mathrm{MeOH}$, respectively. Purified extracts were dried up using a centrifugal vacuum concentrator, reconstructed in $10 \%(\mathrm{v} / \mathrm{v}) \mathrm{MeOH}$ and passed through Waters SPE MCX cartridge for removing ion pollutions. Cartridges were previously activated and equilibrated with $5 \%(\mathrm{v} / \mathrm{v})$ FA in 5\% (v/v) MeOH, 5\% (v/v) MeOH, 5\% (v/v) $\mathrm{NH}_{4} \mathrm{OH}$ in $5 \%(\mathrm{v} / \mathrm{v}) \mathrm{MeOH}$ and $5 \%(\mathrm{v} / \mathrm{v}) \mathrm{MeOH}$, respectively. Then samples were eluted using $80 \%(\mathrm{v} / \mathrm{v}) \mathrm{MeOH}$. Eluents were dried up using a centrifugal vacuum concentrator, suspended in $96 \%$ (v/v) EtOH, and derivatized using DMAPBA reagent. Quantification of BR-DMAPBA was performed using the Agilent LC-QToF-MS system. Samples were injected on the Waters XBridge $\mathrm{C}_{18}$ column $(250 \mathrm{~mm} \times 4.6 \mathrm{~mm}, 1.7 \mu \mathrm{m})$; mobile phase A was $0.1 \%(\mathrm{v} / \mathrm{v})$ FA in $\mathrm{H}_{2} \mathrm{O}$, mobile phase B was $0.1 \%$ (v/v) FA in ACN.

\section{Optimization of MS/MS Conditions}

For the optimization of MS/MS conditions, the chemical standards of analyzed phytohormones were directly injected to the MS in positive $\left([\mathrm{M}+\mathrm{H}]^{+}\right)$ion scan modes, then areas of detected standards peaks were calculated. $[\mathrm{M}+\mathrm{H}]^{+}$was chosen because of significantly better signal to noise ratios compared to the negative ion scan modes.

\section{Statistical Analysis}

The R software was used to perform statistical analyses $\mathrm{R}$ Core Team (2019). Data, grouped by phytohormone and treatment $(n=4-5)$, were subjected to the one-way ANOVA ('stats' package) followed by Tukey's post hoc test ['laercio' package (da Silva 2010)]. The Shapiro-Wilk and Levene's tests ['stats' and 'car' packages] were used to verify ANOVA assumptions of Gaussian distributed data with homogenous variances $(\alpha=0.05)$. Pearson's correlations ['Hmisc' package (Harrell 2019)] were calculated to check the linear relationship between each phytohormone $(n=25)$, except BL, HBL, TY, 6dCS, 6dTY, $c Z$ Z9G, $t \mathrm{Z}, t \mathrm{Z} 9 \mathrm{G}, \mathrm{DHZ}$, DHZR, DHZOG, iPR, $o \mathrm{~T}$, and $m \mathrm{~T}$, which were not normally distributed (Table 1S). Thus, all phytohormones were also assessed for a monotonic relationship using Spearman's rank correlations. Resulting correlation matrices were visualized as heatmaps using the 'corrplot' package (Wei and Simko 2017) and network plots, using the 'corrr' package (Kuhn et al. 2020), to simplify, further explore and visualize strong correlations. The projection of data on network plots was handled by multidimensional scaling of the matrix of correlations coefficients absolute values. Correlations were considered significant for $p<0.05$. Linear regression analyses were also performed to model the linear relationship between pairs of phytohormones with $|r| \geq 0.8$ ('stats' package).

\section{Results and Discussion}

\section{Overall Phytohormones Occurrence}

The presence of phytohormones has been evidenced in lower and higher plants, both in gymnosperms and angiosperms species. The most widely contributed hormone is ABA, which also occurs in cyanobacteria (Gayathri et al. 2017), marine sponges (Zocchi et al. 2001), lichens, fungi (Hirai et al. 2000; Hartung 2010), mammals (Sturla et al. 2009), and even in human blood cell (Bruzzone et al. 2007; Magnone et al. 2009) and plasma (Bruzzone et al. 2012). Other phytohormones are also commonly spread in plants. Regarding the CKs, most scientific reports present its identification and abundance within Brassicaceae family, particularly in Arabidopsis thaliana and Brassica napus (Luo et al. 2017; Šimura et al. 2018). The presence of GAs is evidenced in algae (Stirk et al. 2013a), vascular plants (MacMillan 2001; Pan et al. 2010), and fungi (Hedden and Thomas 2012). Furthermore, the distribution of the above phytohormones is reported in many genera of cyanobacteria and a few species of diatoms (Stirk et al. 2013b; Lu and Xu 2015). BRs have been identified so far in over twenty species of algae (mainly in Chlorophyceae) (Bajguz 2009; Stirk et al. 2013a; Bajguz 2019), one species of bryophyte (Equisetum arvanse), one pteridophyte (Marchantia polymorpha), two lycophytes (Selaginella moellendorffii and $S$. uncinata), thirteen fern species (Yokota et al. 2017), gymnosperms with genus of Cupressus and Pinus, and in angiosperms belonging to the family of Fagaceae, Apiaceae, Brassicaceae, Fabaceae, Poaceae, Solanaceae, and others (Bajguz et al. 2019; Janeczko 2019; Zullo and Bajguz 2019). Furthermore, the presence of BRs has been confirmed in all plant organs (Bajguz and Tretyn 2003; Tarkowská et al. 2016; Kanwar et al. 2017; Tarkowska and Strnad 2018). However, there are no data on the occurrence of phytohormones in the Lemnaceae family.

\section{Endogenous Content of Phytohormones in W. arrhiza and Effect of Cadmium on Their Content}

Quantification of phytohormones under the influence of Cd in W. arrhiza is presented in Table 1. Obtained results are based on the previously prepared standard curves of phytohormone content, and each value has been calculated on $1 \mathrm{~g}$ of fresh weight (FW). Regarding the control group, phytohormones occur in a wide range from 0.016 to $55.541 \mathrm{ng} \mathrm{g}^{-1} \mathrm{FW}$. Thus, the LC-QToF-MS analysis indicated the presence of ABA, eight BRs (CT, TY, 6dTY, $\mathrm{CS}, 6 \mathrm{dCS}, \mathrm{ECS}, \mathrm{BL}$, and HBL), five isoprenoid free bases 
Table 1 The phytohormones level (ng $\mathrm{g}^{-1}$ fresh weight) in Wolffia arrhiza treated with $\mathrm{Cd}$

\begin{tabular}{|c|c|c|c|c|c|}
\hline & Control & $0.1 \mu \mathrm{M} \mathrm{Cd}$ & $1 \mu \mathrm{M} \mathrm{Cd}$ & $10 \mu \mathrm{M} \mathrm{Cd}$ & $100 \mu \mathrm{M} \mathrm{Cd}$ \\
\hline ABA & $0.348 \pm 0.128^{c}$ & $0.448 \pm 0.071^{\mathrm{c}}$ & $0.532 \pm 0.075^{\mathrm{bc}}$ & $0.7 \pm 0.05^{\mathrm{b}}$ & $1.011 \pm 0.141^{\mathrm{a}}$ \\
\hline $\mathrm{GA}_{3}$ & $55.541 \pm 4.028^{\mathrm{a}}$ & $47.951 \pm 2.011^{\mathrm{b}}$ & $43.464 \pm 3.28^{\mathrm{b}}$ & $32.443 \pm 2.322^{\mathrm{c}}$ & $25.136 \pm 2.247^{\mathrm{c}}$ \\
\hline $6 \mathrm{dTY}$ & $0.897 \pm 0.081^{b}$ & $1.061 \pm 0.141^{\mathrm{b}}$ & $0.998 \pm 0.086^{\mathrm{b}}$ & $1.559 \pm 0.159^{\mathrm{a}}$ & $0.774 \pm 0.114^{b}$ \\
\hline CT & $1.709 \pm 0.437^{c}$ & $3.55 \pm 0.293^{c}$ & $7.006 \pm 0.73^{\mathrm{a}}$ & $6.621 \pm 0.47^{\mathrm{a}}$ & $5.062 \pm 0.4^{\mathrm{b}}$ \\
\hline TY & $0.351 \pm 0.033^{b}$ & $0.348 \pm 0.027^{b}$ & $0.531 \pm 0.027^{b}$ & $0.913 \pm 0.156^{\mathrm{a}}$ & $0.514 \pm 0.077^{b}$ \\
\hline $6 \mathrm{dCS}$ & $0.106 \pm 0.032^{c}$ & $0.135 \pm 0.006^{\mathrm{c}}$ & $0.177 \pm 0.016^{\mathrm{c}}$ & $0.343 \pm 0.037^{\mathrm{b}}$ & $0.807 \pm 0.037^{\mathrm{a}}$ \\
\hline CS & $3.821 \pm 0.184^{\mathrm{abc}}$ & $4.004 \pm 0.201^{\mathrm{ab}}$ & $4.568 \pm 0.27^{\mathrm{a}}$ & $3.698 \pm 0.241^{\mathrm{bc}}$ & $3.133 \pm 0.606^{\mathrm{c}}$ \\
\hline ECS & $1.067 \pm 0.086^{\mathrm{a}}$ & $1.024 \pm 0.11^{\mathrm{a}}$ & $0.72 \pm 0.124^{\mathrm{b}}$ & $0.524 \pm 0.095^{\mathrm{b}}$ & $0.52 \pm 0.043^{\mathrm{b}}$ \\
\hline BL & $0.179 \pm 0.027^{b}$ & $0.174 \pm 0.017^{\mathrm{b}}$ & $0.264 \pm 0.132^{\mathrm{b}}$ & $0.464 \pm 0.109^{b}$ & $1.697 \pm 0.19^{\mathrm{a}}$ \\
\hline HBL & $1.401 \pm 0.315^{\mathrm{c}}$ & $1.356 \pm 0.093^{c}$ & $1.744 \pm 0.227^{\mathrm{bc}}$ & $2.342 \pm 0.048^{\mathrm{b}}$ & $3.656 \pm 0.348^{\mathrm{a}}$ \\
\hline$t \mathrm{Z}$ & $23.235 \pm 1.7^{\mathrm{b}}$ & $22.614 \pm 1.931^{\mathrm{b}}$ & $33.619 \pm 3.194^{\mathrm{a}}$ & $24.577 \pm 1.283^{\mathrm{b}}$ & $5.261 \pm 0.751^{\mathrm{c}}$ \\
\hline$t \mathrm{ZR}$ & $7.332 \pm 1.588^{\mathrm{c}}$ & $17.285 \pm 2.684^{\mathrm{b}}$ & $27.36 \pm 2.94^{\mathrm{a}}$ & $13.876 \pm 1.92^{\mathrm{b}}$ & $2.775 \pm 0.776^{\mathrm{c}}$ \\
\hline$t \mathrm{Z} 9 \mathrm{G}$ & $0.185 \pm 0.091^{\mathrm{a}}$ & $0.232 \pm 0.045^{\mathrm{a}}$ & $0.102 \pm 0.015^{\mathrm{a}}$ & $0.341 \pm 0.491^{\mathrm{a}}$ & $0.068 \pm 0.013^{\mathrm{a}}$ \\
\hline$t \mathrm{Z7G}$ & $0.03 \pm 0.006^{b c}$ & $0.032 \pm 0.002^{b c}$ & $0.038 \pm 0.009^{\mathrm{ab}}$ & $0.046 \pm 0.003^{\mathrm{a}}$ & $0.02 \pm 0.005^{\mathrm{c}}$ \\
\hline$t$ ZROG & $0.205 \pm 0.035^{\mathrm{c}}$ & $0.283 \pm 0.096^{b c}$ & $0.52 \pm 0.088^{\mathrm{a}}$ & $0.432 \pm 0.108^{\mathrm{ab}}$ & $0.449 \pm 0.046^{\mathrm{a}}$ \\
\hline$c \mathrm{Z}$ & $20.52 \pm 1.769^{a}$ & $15.918 \pm 1.839^{\mathrm{b}}$ & $11.306 \pm 0.843^{c}$ & $9.357 \pm 0.635^{\mathrm{c}}$ & $2.236 \pm 0.178^{c}$ \\
\hline$c \mathrm{Z9G}$ & $0.027 \pm 0.004^{\mathrm{c}}$ & $0.605 \pm 0.116^{\mathrm{a}}$ & $0.692 \pm 0.118^{\mathrm{a}}$ & $0.549 \pm 0.088^{a b}$ & $0.386 \pm 0.071^{b}$ \\
\hline DHZ & $0.071 \pm 0.009^{c}$ & $0.338 \pm 0.013^{\mathrm{b}}$ & $0.479 \pm 0.089^{\mathrm{a}}$ & $0.27 \pm 0.01^{\mathrm{b}}$ & $0.049 \pm 0.013^{c}$ \\
\hline DHZR & $2.518 \pm 0.395^{\mathrm{c}}$ & $5.682 \pm 0.667^{b}$ & $7.469 \pm 0.852^{\mathrm{a}}$ & $4.077 \pm 0.762^{\mathrm{c}}$ & $3.036 \pm 0.817^{c}$ \\
\hline DHZOG & $4.683 \pm 0.838^{c}$ & $15.429 \pm 0.919^{\mathrm{a}}$ & $12.726 \pm 1.264^{\mathrm{b}}$ & $8.28 \pm 0.777^{\mathrm{c}}$ & $4.479 \pm 1.073^{c}$ \\
\hline iP & $0.375 \pm 0.105^{\mathrm{a}}$ & $0.292 \pm 0.075^{\mathrm{a}}$ & $0.434 \pm 0.1^{\mathrm{a}}$ & $0.33 \pm 0.046^{\mathrm{a}}$ & $0.048 \pm 0.01^{\mathrm{b}}$ \\
\hline iPR & $0.083 \pm 0.017^{\mathrm{c}}$ & $0.222 \pm 0.057^{\mathrm{c}}$ & $0.405 \pm 0.035^{\mathrm{c}}$ & $1.064 \pm 0.166^{\mathrm{a}}$ & $0.722 \pm 0.104^{b}$ \\
\hline iPR7G & $0.383 \pm 0.109^{c}$ & $2.662 \pm 0.442^{\mathrm{b}}$ & $3.474 \pm 0.362^{\mathrm{a}}$ & $2.038 \pm 0.634^{\mathrm{bc}}$ & $1.393 \pm 0.227^{\mathrm{c}}$ \\
\hline$o \mathrm{~T}$ & $0.287 \pm 0.041^{\mathrm{c}}$ & $0.509 \pm 0.072^{\mathrm{c}}$ & $0.586 \pm 0.038^{b c}$ & $0.71 \pm 0.044^{\mathrm{b}}$ & $1.563 \pm 0.104^{\mathrm{a}}$ \\
\hline$m \mathrm{~T}$ & $0.016 \pm 0.002^{c}$ & $0.078 \pm 0.014^{b c}$ & $0.142 \pm 0.012^{b c}$ & $0.187 \pm 0.017^{b}$ & $0.81 \pm 0.139^{\mathrm{a}}$ \\
\hline
\end{tabular}

Data, grouped by treatment for each phytohormone, represent the mean $(n=4-5) \pm$ standard deviation. The same letters indicate statistically nonsignificant differences, according to Tukey's post hoc test $(p \geq 0.05)$ of CKs ( $t \mathrm{Z}, c \mathrm{Z}, \mathrm{DHZ}, \mathrm{iP}$, and iPR), two aromatic free bases of CKs ( $o \mathrm{~T}$ and $m \mathrm{~T}$ ), eight conjugates of CKs ( $t \mathrm{ZR}, t \mathrm{Z9G}$, $t$ Z7G, $t$ ZROG, $c$ Z9G, DHZR, DHZOG, and iPR7G), and $\mathrm{GA}_{3}$. The total number of detected compounds is 25 . This is the first report about the presence of plant hormones not only in W. arrhiza but also in Lemnaceae plants. This study showed that the most widely contributed phytohormones are CKs, which are represented by 15 compounds. Among all detected phytohormones, the highest content of $\mathrm{GA}_{3}$ and $t \mathrm{Z}$ was noted (55.541 and $23.235 \mathrm{ng} \mathrm{g}^{-1} \mathrm{FW}$, respectively). The total level of hormone groups in duckweed exposed to $\mathrm{Cd}$ is presented in Fig. 1. Therefore, the total content of ABA and BRs increased while $\mathrm{GA}_{3}$ amount decreased in the presence of $\mathrm{Cd}$. While the level of CKs in plant exposed to $0.1,1$, and $10 \mu \mathrm{M} \mathrm{Cd}$ was higher than control, but in plant treated of $100 \mu \mathrm{M} \mathrm{Cd}$ was lower.

The correlation analysis of phytohormones in W. arrhiza revealed very strong, negative linear relations between ABA vs. $\mathrm{GA}_{3}, \mathrm{ECS}$, and $c \mathrm{Z} ; \mathrm{GA}_{3}$ vs. iPR; and ECS vs. iPR [according to Evans (1996)] (Fig. 2a, b), while positive was found between $\mathrm{GA}_{3}$ vs. ECS and $c \mathrm{Z}$; ECS vs. $c \mathrm{Z}$; CT vs. $t Z R R G$; and $t Z R$ vs. iPR7G. Ten linear regressions models and equations were calculated and presented for those pairs of phytohormones (Fig. $2 \mathrm{a}$ ), e.g., ABA $\approx 1.404$ $-0.019 \times \mathrm{GA}_{3}$. Thus, the precise relationship was identified in this research. Furthermore, strong, negative monotonic relations were found between, e.g., $c \mathrm{Z}$ vs. $o \mathrm{~T}, m \mathrm{~T}$, iPR, $6 \mathrm{dCS}$, IAA, BL, and HBL; HBL vs. $\mathrm{GA}_{3}$ and ECS; IAA vs. $\mathrm{GA}_{3}$; ECS vs. 6dCS. Positive ones were noted between, e.g., BL vs. iPR, $o$ T, $m$ T, IAA, ABA, 6dCS, and HBL; TY vs. iPR, $m$ T, IAA, 6dCS, and HBL; DHZR vs. $c Z 9 G$, DHZ, DHZOG, iPR7G, $t$ ZR, IPA, and CS (Fig. 3a, b).

$\mathrm{ABA}$, as an essential hormone during heavy metal stress, is synthesized through the methylerythritol phosphate (MEP) or methylerythritol phosphate (MVA) pathway. Their precursor is isopentenyl pyrophosphate (IPP), which is synthesized in higher plants through MEP in the cytosol and MVA in the plastid, whereas in algae exclusively through MEP in the cytosol. Transformations of IPP led to the origin of xanthophyll, which are direct precursors of ABA (Maršálek and Šimek 1992; Cutler and Krochko 1999; Li et al. 2017; Olds et al. 2018). Biosynthesis of ABA significantly increases under stress conditions, e.g., salinity, drought, cold temperature, or heavy metals (Khan et al. 2020), therefore the 
Fig. 1 The total content of phytohormones (ng g ${ }^{-1}$ fresh weight) in $W$. arrhiza treated with cadmium

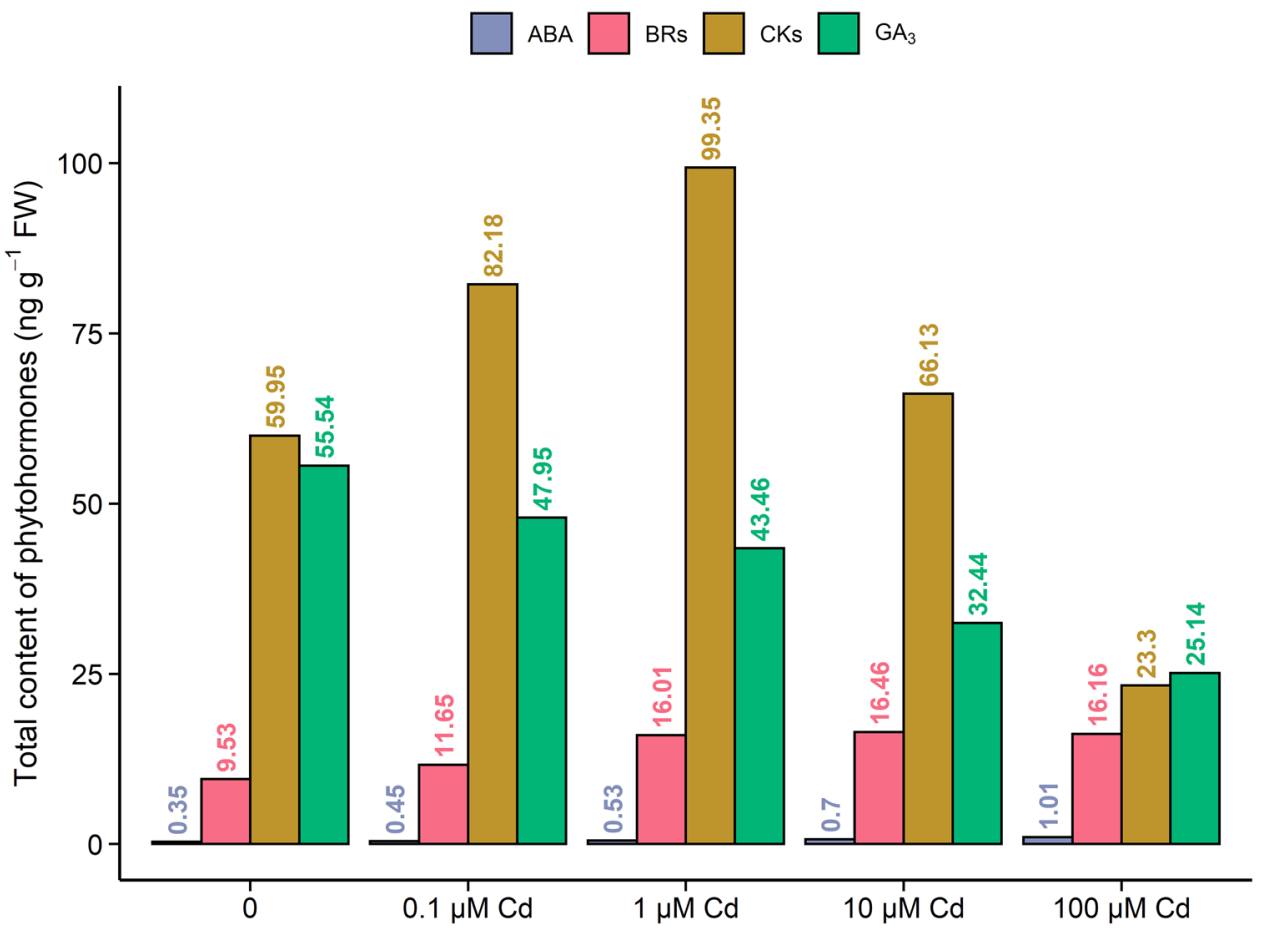

endogenous level of ABA enhanced under the influence of $\mathrm{Cd}$, reached the highest value for $100 \mu \mathrm{M} \mathrm{Cd}\left(1.011 \mathrm{ng} \mathrm{g}^{-1}\right.$ FW, Table 1, Fig. 1) in W. arrhiza. Thus, this is almost a threefold increase comparing to untreated duckweed.

Biosynthesis of BRs is a multistep process, including three independent pathways for creating $\mathrm{C}_{27}, \mathrm{C}_{28}$, and $\mathrm{C}_{29}$ types of BRs. During this research, compounds belonging to the $\mathrm{C}_{28}$ type were identified, except HBL, which has 29 atoms of carbon. Synthesis of $\mathrm{C}_{28}$ BRs can occur in both early and late oxidation pathway from campestanol $(\mathrm{CN})$, which is a direct precursor of this BRs biosynthesis type. During the early $\mathrm{C} 6$ oxidation pathway, $\mathrm{CN}$ is hydroxylated in C-6 position to $6 \alpha$-hydroxycampesterol, which is oxidized to 6-oxocampestanol (6-oxoCN). It is hydroxylated in $\mathrm{C}-22$ position to the first of BR - CT. Next, CT is hydroxylated in $\mathrm{C}-23$ position to TE, which is converted in 3-dehydroteasterone, and this BR is reduced in $\mathrm{C}-3$ position to TY. Then, TY is hydroxylated in C-2 position to CS, which is oxidized in $\mathrm{C}-7$ position to $\mathrm{BL}$. Whereas in the late $\mathrm{C}_{6}$ oxidation pathway, $\mathrm{CN}$ is converted to $6 \mathrm{dCT}$, which is hydroxylated to 6dTE, the next 6dTE is reduced to 3-dehydro-6dTE and this compound is hydroxylated to $6 \mathrm{dTY}$ which is hydroxylated in $\mathrm{C}-2$ position to $6 \mathrm{dCS}$. Next, $6 \mathrm{dCS}$ after a hydroxylation to 6-hydroxyCS is oxidized in C-6 position to CS, which is oxidized to BL (Wang et al. 2017; Ohnishi 2018). In the present study, the presence of hydroxylated and no hydroxylated forms of BRs was reported. The occurrence of TY (a direct precursor of CS biosynthesis in the early $\mathrm{C}_{6}$ pathway) and 6dCS (a precursor of CS during the late C6 pathway) shows that the biosynthesis of BRs in W. arrhiza can occur in both pathways. The previous study of Bajguz and Asami (2005) indicates that the addition of brassinazole (a specific BR biosynthesis inhibitor) to $W$. arrhiza cultures inhibits their growth, which was reversed by exogenous EBL. Brassinazole blocks the conversion of $\mathrm{CN}$ to $6 \mathrm{dCT}, 6 \mathrm{dCT}$ to 6dTE, 6-oxoCN to CT, and CT to TE (Asami and Yoshida 1999; Rozhon et al. 2019). It confirms that BRs are essential to the normal growth of $W$. arrhiza. In this study, among untreated with Cd plants, the largest content of CS and CT was noted (3.821 and $1.709 \mathrm{ng} \mathrm{g}^{-1} \mathrm{FW}$, respectively). Sitosterol, as a precursor of $\mathrm{C}_{29}$ biosynthesis, is transformed into 28-homoTY, which then is converted to 28-homoCS and HBL (Roh et al. 2017). The presence of HBL in W. arrhiza suggests the occurrences of the $\mathrm{C}_{29}$ biosynthesis pathway in this duckweed. Whereas $\mathrm{C}_{27}$ type of BR, i.e., 28-norBL has not been detected. However, many $\mathrm{C}_{27}$ compounds, e.g., 28-norCT, 28-norTE, 28-norTY, 28-norCS, have not been noted. Thus, the presence of the $\mathrm{C}_{27}$ pathway cannot be excluded. Differences between amount and distribution of various types of BRs are related with family, e.g., Brassicaceae, Poaceae, or Solanaceae (Bajguz and Tretyn 2003; Verhoef et al. 2013; Xin et al. 2013; Tarkowská et al. 2016; Kanwar et al. 2017; Tarkowska and Strnad 2018; Bajguz et al. 2019; Janeczko 2019; Li et al. 2019). Exposure of $W$. arrhiza culture on Cd caused an increase of the endogenous level of BRs in relation to control (Table 1), except ECS, whose amount decreased. The level of $6 \mathrm{dCS}, \mathrm{BL}$, and HBL increased proportionally to the rising of $\mathrm{Cd}$ concentration. In the case of 6dTY and TY the largest value noticed in plant treated with $10 \mu \mathrm{M} \mathrm{Cd}$, while the level of CT and CS was 
A

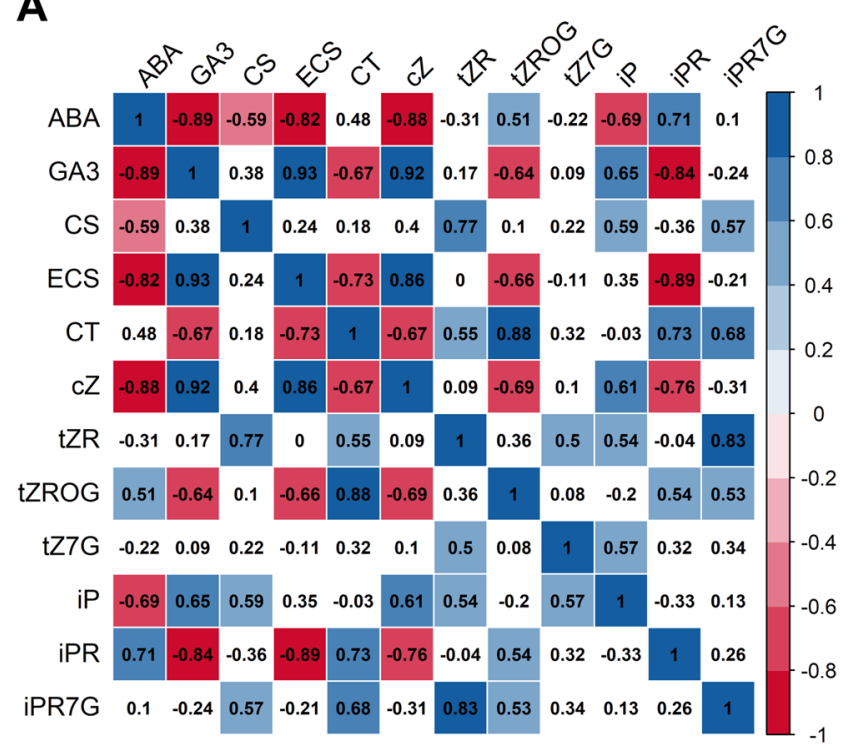

B

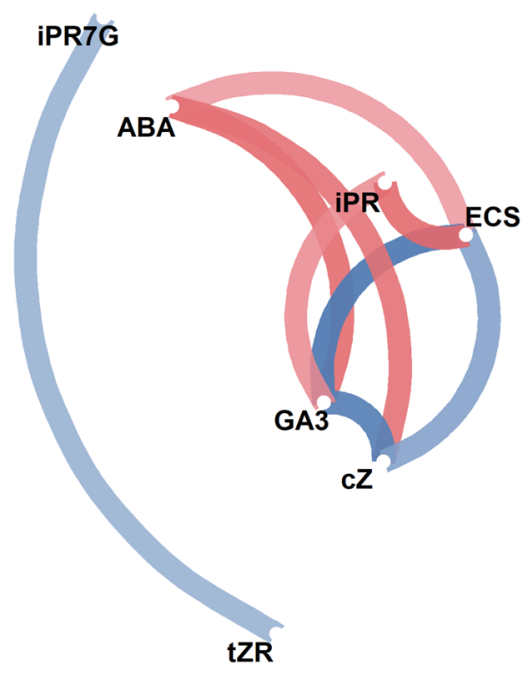

Fig. 2 a Correlation heatmap for phytohormones $(n=22)$ in Wolffia arrhiza with equations obtained from linear regression. The colored and labeled scale codes for the value of Pearson's correlation coefficient $r$. Positive correlations are blue, while negative correlations

the highest in $1 \mu \mathrm{M} \mathrm{Cd}$. Bali et al. (2019) show the positive effect of exogenously applied BRs on Cd treated plant, e.g., HBL increases the activity of antioxidants and overcomes the inhibition of plant growth, but there are no data about the endogenous level of BRs in plants exposed to Cd. However, increased biosynthesis of BRs in duckweed exposed to $\mathrm{Cd}$ (Fig. 1) confirmed the role of BRs in the response of plants to the heavy metal stress.

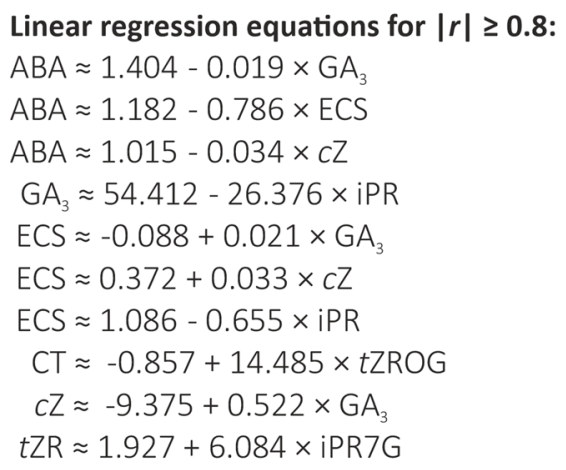

iP
tZ7G

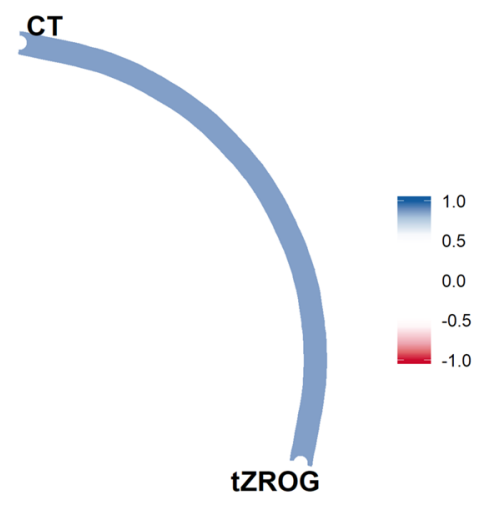

CS are red. White squares show nonsignificant correlations $(p \geq 0.05)$. b Multidimensional scaling network plot of the absolute values of $r \geq 0.8$ (Color figure online)

In lower plants (mosses, green algae, ferns, horsetails), CKs have been only identified as free bases of $c \mathrm{Z}$ and iPR; and their riboside conjugates, whereas in higher plants occurrence of all currently known free bases types and conjugates of CKs was reported (Stirk and van Staden 2003; Bajguz and Piotrowska 2009; Aremu et al. 2012). Biosynthesis of CK isoprenoid occurs through the transfer of $\mathrm{C}_{5}$ isoprenoid unit to adenine molecule that may be a free 
Fig. 3 a Correlation heatmap for phytohormones $(n=22)$ in Wolffia arrhiza. The colored and labeled scale codes for the value of the Spearman's rank correlation coefficient $r_{\mathrm{s}}$. Positive correlations are blue, while negative correlations are red. White squares show nonsignificant correlations $(p \geq 0.05)$. b Multidimensional scaling network plot of the absolute values of $r_{\mathrm{s}} \geq 0.8$ (Color figure online)
A

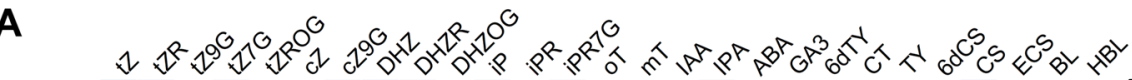

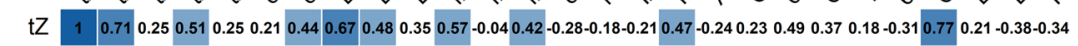

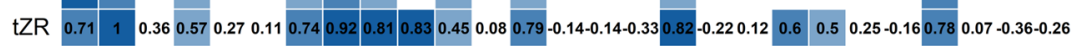

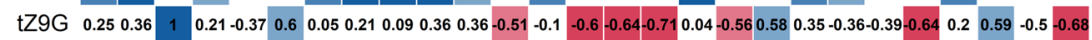

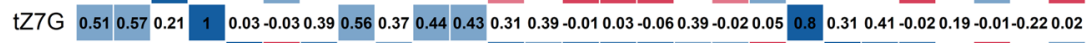

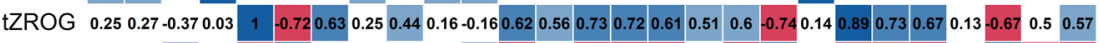

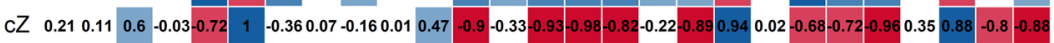

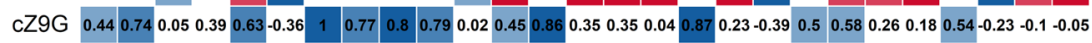

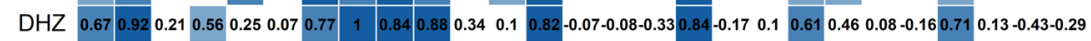

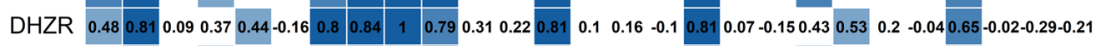

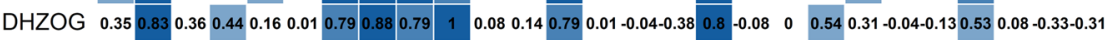

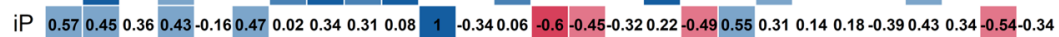

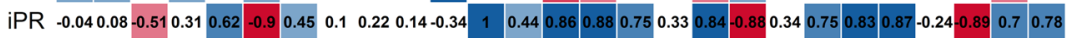

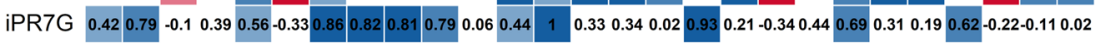

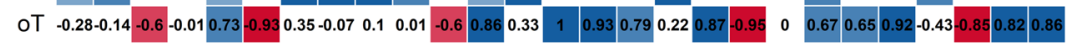

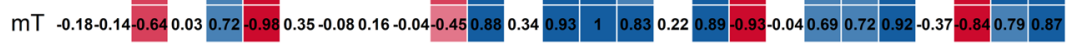

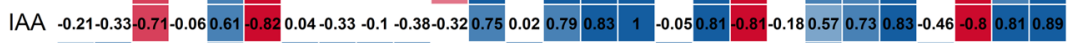

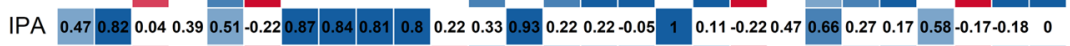

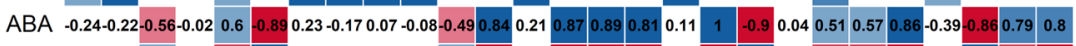

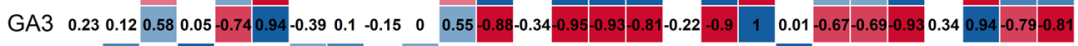

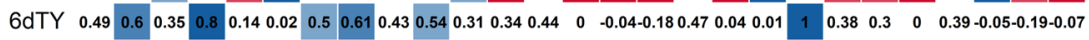

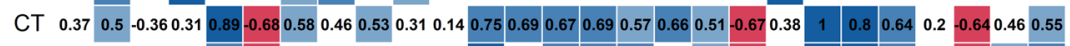

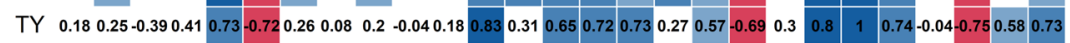

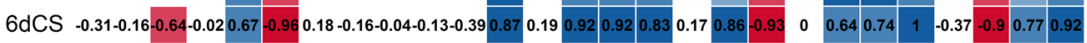
$\begin{array}{lllllllllllllllllllllllllllll}\text { CS } & 0.77 & 0.78 & 0.2 & 0.19 & 0.13 & 0.35 & 0.54 & 0.71 & 0.65 & 0.53 & 0.43 & -0.24 & 0.62 & -0.43-0.37-0.46 & 0.58 & -0.39 & 0.34 & 0.39 & 0.2 & -0.04-0.37 & 1 & 0.23 & -0.5 & -0.48\end{array}$

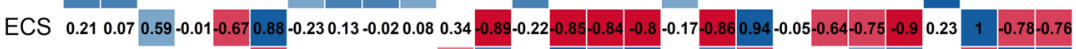

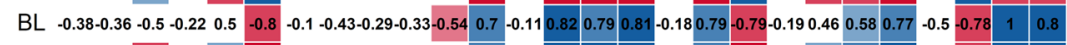

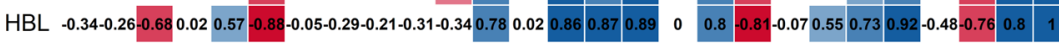

B

iP

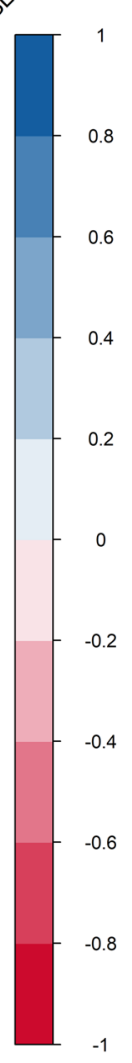

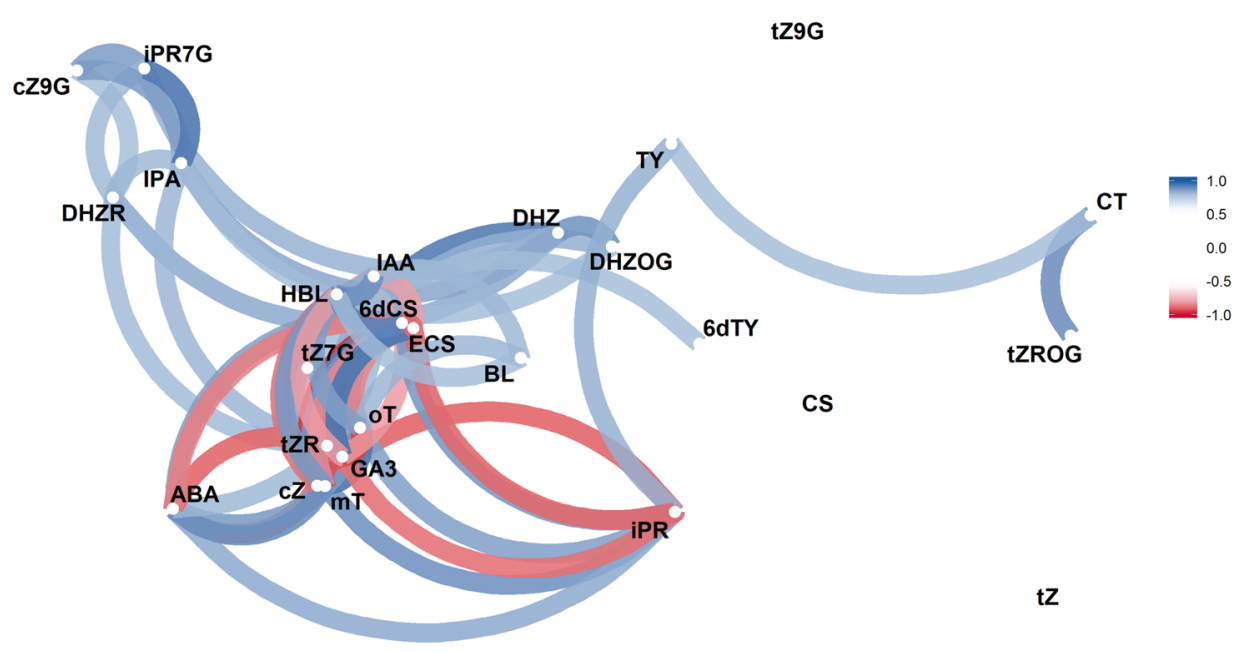

nucleotide (AMP, ADP, or ATP) or bound with tRNA. There are two donors of $\mathrm{C}_{5}$ isoprenoid, first of them is dimethylallyl pyrophosphate that is synthesized during a MEP or MVA pathway, second of them is 4-hydroxy-3-methyl-2-(E)-butenyl diphosphate that is formed only by MEP. These reactions are catalyzed by adenylate isopentenyl transferases. Then, obtained compounds are hydroxylated to $t Z$ by cytochrome
P450 monooxygenase. CKs are also produced by the degradation of tRNA, and this is the main source of CKs isoprenoids forms in cis configuration (Frébort et al. 2011; Kieber and Schaller 2014; Feng et al. 2017; Tarkowska and Strnad 2018). Our results indicate the presence of fifteen forms of CKs and show the effect of $\mathrm{Cd}$ application on their content (Table 1, Fig. 1). Regarding the control, the results include 
$44.284 \mathrm{ng} \mathrm{g}^{-1} \mathrm{FW}$ of isoprenoid free bases, $0.303 \mathrm{ng} \mathrm{g}^{-1} \mathrm{FW}$ of aromatic free bases, and $15.363 \mathrm{ng} \mathrm{g}^{-1} \mathrm{FW}$ conjugates of CKs in W. arrhiza. Furthermore, the presence of CKs either in cis or trans orientations was reported. Among all detected CKs, the highest content of $t \mathrm{Z}$, and $c \mathrm{Z}$ was noted (23.235 and $20.52 \mathrm{ng} \mathrm{g}^{-1} \mathrm{FW}$, respectively). While due to the chemical form of CKs; $t$ Z, $c$ Z-types are the predominant (30.987 and $20.547 \mathrm{ng} \mathrm{g}^{-1} \mathrm{FW}$, respectively), DHZ-type occurs in less amount (7.272 $\left.\mathrm{ng} \mathrm{g}^{-1} \mathrm{FW}\right)$ and iP-type of CKs presents in low amount, i.e., $0.841 \mathrm{ng} \mathrm{g}^{-1}$ FW. Generally, the endogenous level of CKs after application of $\mathrm{Cd}$ was higher than in control; however, a concentration of $100 \mu \mathrm{M} \mathrm{Cd}$ for several compounds caused inhibition of their synthesis. For example, the amount of $t \mathrm{Z}$ under the influence of 0.1 and $10 \mu \mathrm{M}$ $\mathrm{Cd}$ was similar to the control, in the plant treated $1 \mu \mathrm{M} \mathrm{Cd}$ significantly increased, while in $100 \mu \mathrm{M}$ of $\mathrm{Cd}$ decreased. Merely content of $c \mathrm{Z}$ was reduced in all concentrations of Cd compared to the control. However, the overall content of CKs in duckweed exposed to the $0.1-10 \mu \mathrm{M} \mathrm{Cd}$ was larger to untreated plant, but the application of $100 \mu \mathrm{M} \mathrm{Cd}$ caused a considerable decline of CKs level (Fig. 1, Table 1). Zhou et al. (2019) also demonstrated a slight increase of total CKs concentration in Kosteletzkya pentacarpos seedlings in the presence of $10 \mu \mathrm{M} C d$ to control. Interestingly, they indicated a positive effect of exogenously applied $t$ ZR on plant treated with $10 \mu \mathrm{M} \mathrm{Cd}$, which can explain the enhanced biosynthesis of $t Z R$ in present results. The application of $100 \mu \mathrm{M} \mathrm{Cd}$ also caused a decrease of $\mathrm{Z}$ and $\mathrm{ZR}$ levels in soybean (Hashem 2014) and W. arrhiza (Table 1). The percentage content of types of CKs in duckweed with the addition of $\mathrm{Cd}$ is presented in Fig. 4. Free bases of CKs are the most widespread in W. arrhiza, but in a group with $\mathrm{Cd}$ their predominance over conjugates is lower comparing to the control group. Consequently, an increased proportion of all CKs conjugates to free bases in plants treated with $\mathrm{Cd}$ was noted. The percentage of $O$-glucoside forms increased from $16.57 \%$ in control up to about $30 \%$ in exposure to $\mathrm{Cd}$ plant. The contribution of riboside and $\mathrm{N}$-glucosides conjugates also was enhanced. Despite the conviction that $t \mathrm{Z}$ and iP forms are the dominant types of CKs; there are reports about the dominance of $c \mathrm{Z}$ in many plants, e.g., in potatoes, rice, maize, and legumes (Gajdošová et al. 2011; Murai 2014; Schäfer et al. 2015). In the current research, $t Z$ is a basic and most common form of CKs; however, the occurrence of iP form is limited. The primary function of CKs is the stimulation of cell division and the prevention of cells aging (Sosnowski et al. 2019). Moreover, Kurepa et al. (2018) reported the positive correlation between exogenous applied of 6-benzyladenine and increases of cell size and division in two species of duckweeds (Spirodela polyrhiza and Lemna gibba). It confirms the importance of CKs in both grown and development of Lemnaceae plants.

In higher plants, the most frequently active forms of GAs are $\mathrm{GA}_{1}, \mathrm{GA}_{3}$, and $\mathrm{GA}_{4}$. The first step of GAs biosynthesis is a transformation of geranylgeranyl diphosphate to the entkaurene in the plastid, then conversion of ent-kaurene to the
Fig. 4 The percentage share of different types of cytokinins: free bases $(t \mathrm{Z}, c \mathrm{Z}, \mathrm{DHZ}, \mathrm{iP}, o \mathrm{~T}$, $m \mathrm{~T})$ and conjugates: $N$-glucosides $(t Z 9 G, t Z 7 G$, iPR7G), $O$-glucosides $(t Z R O G, c Z 9 G$, DHZOG), ribosides ( $t Z R$, DHZR, iPR) in Wolffia arrhiza treated with cadmium

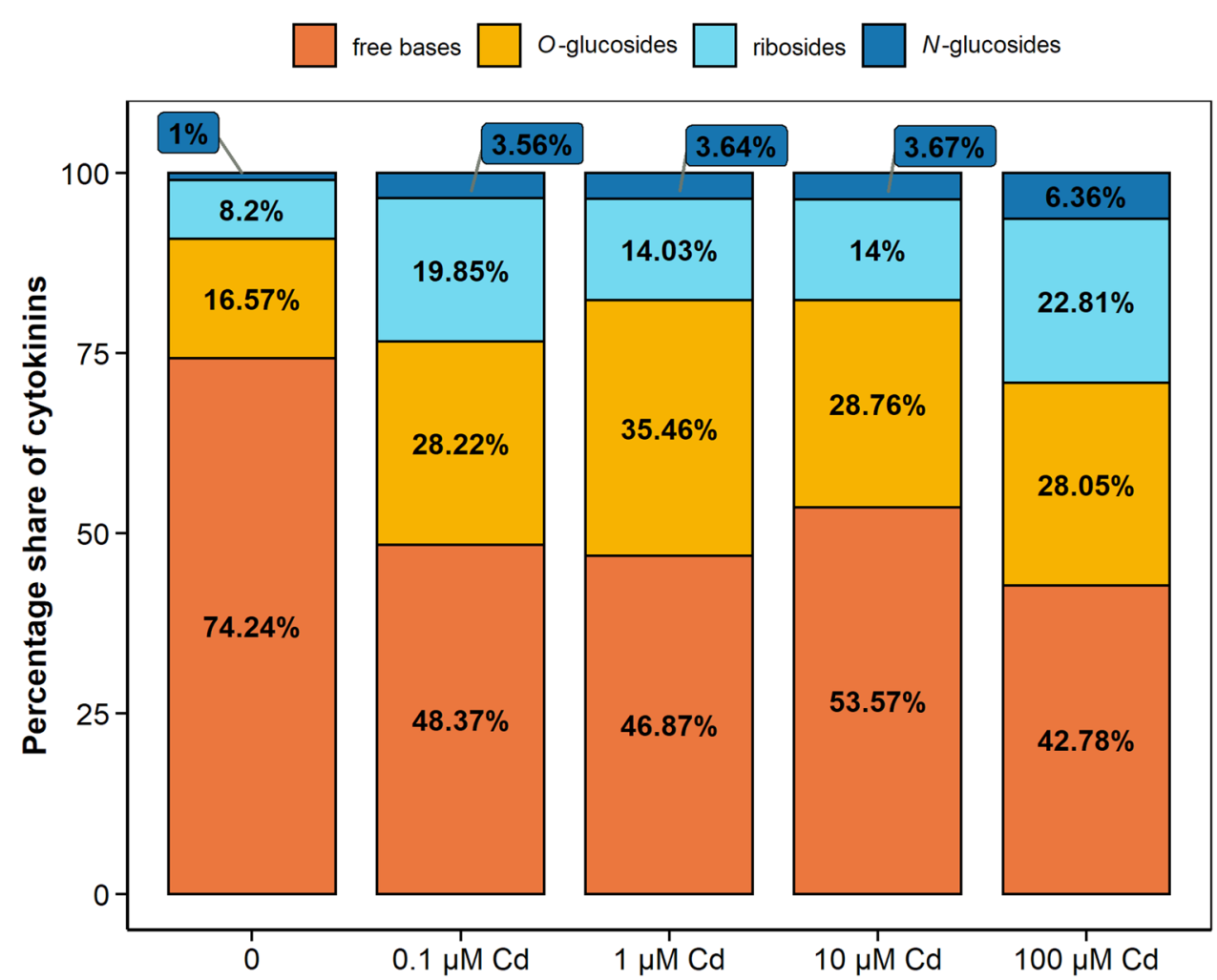


various intermediates until the synthesis of $\mathrm{GA}_{12}$ aldehyde in the endoplasmic reticulum, finally a synthesis of $\mathrm{GA}_{3}$ from $\mathrm{GA}_{12}$ in the cytosol. Several ent-kaurene oxidation steps lead to the formation of $\mathrm{GA}_{12}$ aldehyde, whereas the formation of $\mathrm{GA}_{12}$ occurs through oxidation of their aldehyde group to the carboxyl group. Further, the conversions of $\mathrm{GA}_{12}$ led to the active synthesis form of GAs, i.e., $\mathrm{GA}_{3}$ (Kasahara et al. 2002; Hedden and Thomas 2012; Gao et al. 2017). The largest content of $\mathrm{GA}_{3}\left(55.541 \mathrm{ng} \mathrm{g}^{-1} \mathrm{FW}\right)$ among all identified phytohormones in W. arrhiza was noted (Table 1). It confirms the finding of Pieterse (1974) that the absence of flowers in duckweed relates to the high level of endogenous $\mathrm{GA}_{3}$. In this study, the flowering of W. arrhiza has not been observed because it is a tropical and subtropical flowering plant. It is thus surprising that the flowering of $W$. arrhiza was discovered for the first time in Central Europe in Germany (Schmitz and Kelm 2017). Therefore, future studies should address the induction of flowering by creating optimal conditions in plant growth cabinets. It is commonly known that phytohormones contribute to the flowering process (Conti 2017); hence, the level of hormones will be examined in $W$. arrhiza. While in the present analysis, the decline of $\mathrm{GA}_{3}$ level proportionally to the increase of $\mathrm{Cd}$ concentration (Fig. 1) was reported. Moreover, recent studies of Zhou et al. (2019) indicated that $10 \mu \mathrm{M} \mathrm{Cd}$ treatment reduced GAs content in Kosteletzkya pentacarpos seedlings. Obtained results suggest the negative effect of $\mathrm{Cd}$ stress on GAs. Atici et al. (2005) showed a decrease of $\mathrm{GA}_{3}$ content in chickpea seeds treated with lead. All the mentioned results suggest the negative effect of $\mathrm{Cd}$ or other heavy metals stress on biosynthesis and endogenous level of GAs.

\section{Conclusion}

In this work, the presence of endogenous isoprenoid-derived phytohormones, and the effect of $\mathrm{Cd}$ on their content is reported for the first time in W. arrhiza. The total number of detected compounds is 25 , and they belong to four groups of phytohormones, i.e., ABA, BRs (eight compounds), CKs (15 compounds), and GAs (one compound). The content of phytohormones, especially BRs, was changed in Cd dosedependent manner. Treatment with $\mathrm{Cd}$ causes an increase in the content of ABA, BRs, and CKs (except $100 \mu \mathrm{M} \mathrm{Cd}$ ). Simultaneously, the content of $\mathrm{GA}_{3}$ was inversely proportional to the increasing $\mathrm{Cd}$ concentration. Overall, the distribution of ungrouped data showed linear and monotonic dependencies between phytohormones.

Acknowledgements This work was funded by the Ministry of Science and Higher Education as part of subsidies for maintaining research potential awarded to the Faculty of Biology of the University of Bialystok. This project has also been financed from the funds of the Faculty of Biology and Chemistry of the University of Bialystok allocated based on decision number BMN-153. The equipment of Center BioNanoTecho University of Bialystok (QToF LC/MS) was partially supported by EU funds via Project number POPW.01.03.00-20-004/11.We thank Prof. Izabela Święcicka (Department of Microbiology, University of Bialystok) for lending a vacuum centrifuge.

Author contributions Concept of the study: AB. Analysis and interpretation of MS data: all authors. Preparing a draft of the manuscript: MC. Final approval of manuscript: all authors.

\section{Compliance with Ethical Standards}

Conflict of interest The authors declare that the research was conducted in the absence of any commercial relationships, and there was no potential conflict of interest.

Open Access This article is licensed under a Creative Commons Attribution 4.0 International License, which permits use, sharing, adaptation, distribution and reproduction in any medium or format, as long as you give appropriate credit to the original author(s) and the source, provide a link to the Creative Commons licence, and indicate if changes were made. The images or other third party material in this article are included in the article's Creative Commons licence, unless indicated otherwise in a credit line to the material. If material is not included in the article's Creative Commons licence and your intended use is not permitted by statutory regulation or exceeds the permitted use, you will need to obtain permission directly from the copyright holder. To view a copy of this licence, visit http://creativecommons.org/licenses/by/4.0/.

\section{References}

Aremu AO, Bairu MW, Novák O, Plačková L, Zatloukal M, Doležal K, Finnie JF, Strnad M, Van Staden J (2012) Physiological responses and endogenous cytokinin profiles of tissue-cultured 'Williams' bananas in relation to roscovitine and an inhibitor of cytokinin oxidase/dehydrogenase (INCYDE) treatments. Planta 236:17751790. https://doi.org/10.1007/s00425-012-1721-z

Asami T, Yoshida S (1999) Brassinosteroid biosynthesis inhibitors. Trends Plant Sci 4:348-353. https://doi.org/10.1016/S1360 -1385(99)01456-9

Atici Ö, Ağar G, Battal P (2005) Changes in phytohormone contents in chickpea seeds germinating under lead or zinc stress. Biol Plant 49:215-222. https://doi.org/10.1007/s10535-005-5222-9

Bai Y, Du F, Bai Y, Liu H (2010) Determination strategies of phytohormones: recent advances. Anal Methods 2:1867-1873. https:// doi.org/10.1039/C0AY00471E

Bajguz A (2009) Isolation and characterization of brassinosteroids from algal cultures of Chlorella vulgaris Beijerinck (Trebouxiophyceae). J Plant Physiol 166:1946-1949. https://doi.org/10.1016/j. jplph.2009.05.003

Bajguz A (2019) Brassinosteroids in microalgae: application for growth improvement and protection against abiotic stresses. In: Hayat $S$, Yusuf M, Bhardwaj R, Bajguz A (eds) Brassinosteroids: plant growth and development. Springer, Singapore, pp 45-58. https:// doi.org/10.1007/978-981-13-6058-9_2

Bajguz A, Tretyn A (2003) The chemical characteristic and distribution of brassinosteroids in plants. Phytochemistry 62:1027-1046. https ://doi.org/10.1016/S0031-9422(02)00656-8

Bajguz A, Asami T (2005) Suppression of Wolffia arrhiza growth by brassinazole, an inhibitor of brassinosteroid biosynthesis and its 
restoration by endogenous 24-epibrassinolide. Phytochemistry 66:1787-1796. https://doi.org/10.1016/j.phytochem.2005.06.005

Bajguz A, Piotrowska A (2009) Conjugates of auxin and cytokinin. Phytochemistry 70:957-969. https://doi.org/10.1016/j.phyto chem.2009.05.006

Bajguz A, Orczyk W, Golebiewska A, Chmur M, Piotrowska-Niczyporuk A (2019) Occurrence of brassinosteroids and influence of 24-epibrassinolide with brassinazole on their content in the leaves and roots of Hordeum vulgare L. cv. golden promise. Planta 249:123-137. https://doi.org/10.1007/s00425-018-03081-3

Bali AS, Sidhu GPS, Kumar V, Bhardwaj R (2019) Chapter 15-mitigating cadmium toxicity in plants by phytohormones. In: Hasanuzzaman M, Prasad MNV, Fujita M (eds) Cadmium toxicity and tolerance in plants. Academic Press, London, pp 375-396. https ://doi.org/10.1016/B978-0-12-814864-8.00015-2

Bertin G, Averbeck D (2006) Cadmium: cellular effects, modifications of biomolecules, modulation of DNA repair and genotoxic consequences (a review). Biochimie 88:1549-1559. https://doi. org/10.1016/j.biochi.2006.10.001

Bruzzone S, Moreschi I, Usai C, Guida L, Damonte G, Salis A, Scarfî S, Millo E, De Flora A, Zocchi E (2007) Abscisic acid is an endogenous cytokine in human granulocytes with cyclic ADP-ribose as second messenger. Proc Natl Acad Sci USA 104:5759-5764. https://doi.org/10.1073/pnas.0609379104

Bruzzone S, Ameri P, Briatore L, Mannino E, Basile G, Andraghetti G, Grozio A, Magnone M, Guida L, Scarfì S, Salis A, Damonte G, Sturla L, Nencioni A, Fenoglio D, Fiory F, Miele C, Beguinot F, Ruvolo V, Bormioli M, Colombo G, Maggi D, Murialdo G, Cordera R, De Flora A, Zocchi E (2012) The plant hormone abscisic acid increases in human plasma after hyperglycemia and stimulates glucose consumption by adipocytes and myoblasts. FASEB J 26:1251-1260. https://doi.org/10.1096/fj.11190140

Cao Z-Y, Sun L-H, Mou R-X, Zhang L-P, Lin X-Y, Zhu Z-W, Chen M-X (2016) Profiling of phytohormones and their major metabolites in rice using binary solid-phase extraction and liquid chromatography-triple quadrupole mass spectrometry. J Chromatogr A 1451:67-74. https://doi.org/10.1016/j.chroma.2016.05.011

Chu J, Fang S, Xin P, Guo Z, Chen Y (2017) Quantitative analysis of plant hormones based on LC-MS/MS. In: Li J, Li C, Smith SM (eds) Hormone metabolism and signaling in plants. Academic Press, London, pp 471-537. https://doi.org/10.1016/B978-0-12811562-6.00014-1

Conti L (2017) Hormonal control of the floral transition: Can one catch them all? Dev Biol 430:288-301. https://doi.org/10.1016/j.ydbio 2017.03.024

Cutler AJ, Krochko JE (1999) Formation and breakdown of ABA. Trends Plant Sci 4:472-478. https://doi.org/10.1016/S1360 -1385(99)01497-1

da Silva LJ (2010) Laercio-package: Duncan test, Tukey test and Scott-Knott test. https://CRAN.R-project.org/package=laercio. Accessed $20 \mathrm{Feb} 2015$

Davière J-M, Achard P (2013) Gibberellin signaling in plants. Development 140:1147-1151. https://doi.org/10.1242/dev.087650

Evans JD (1996) Straightforward statistics for the behavioral sciences. Brooks/Cole Pub. Co., Pacific Grove

Feng J, Shi Y, Yang S, Zuo J (2017) Cytokinins. In: Li J, Li C, Smith SM (eds) Hormone metabolism and signaling in plants. Academic Press, London, pp 77-106. https://doi.org/10.1016/B978-0-12811562-6.00003-7

Frébort I, Kowalska M, Hluska T, Frébortová J, Galuszka P (2011) Evolution of cytokinin biosynthesis and degradation. J Exp Bot 62:2431-2452. https://doi.org/10.1093/jxb/err004

Gajdošová S, Spíchal L, Kamínek M, Hoyerová K, Novák O, Dobrev PI, Galuszka P, Klíma P, Gaudinová A, Žižková E, Hanuš J, Dančák M, Trávníček B, Pešek B, Krupička M, Vaňková R, Strnad
M, Motyka V (2011) Distribution, biological activities, metabolism, and the conceivable function of cis-zeatin-type cytokinins in plants. J Exp Bot 62:2827-2840. https://doi.org/10.1093/jxb/ erq457

Gao X, Zhang Y, He Z, Fu X (2017) Gibberellins. In: Li J, Li C, Smith SM (eds) Hormone metabolism and signaling in plants. Academic Press, London, pp 107-160. https://doi.org/10.1016/B978-0-12811562-6.00004-9

Gayathri M, Shunmugam S, Thajuddin N, Muralitharan G (2017) Phytohormones and free volatile fatty acids from cyanobacterial biomass wet extract (BWE) elicit plant growth promotion. Algal Res 26:56-64. https://doi.org/10.1016/j.algal.2017.06.022

Harrell Jr FE (2019) Hmisc: Harrell miscellaneous (R package version 4.2-0). https://CRAN.R-project.org/package $=$ Hmisc. Accessed 26 Jan 2019

Hartung W (2010) The evolution of abscisic acid (ABA) and ABA function in lower plants, fungi and lichen. Funct Plant Biol 37:806-812. https://doi.org/10.1071/FP10058

Hashem HA (2014) Cadmium toxicity induces lipid peroxidation and alters cytokinin content and antioxidant enzyme activities in soybean. Botany 92:1-7. https://doi.org/10.1139/cjb-2013-0164

Hedden P, Thomas SG (2012) Gibberellin biosynthesis and its regulation. Biochem J 444:11-25. https://doi.org/10.1042/bj20120245

Hirai N, Yoshida R, Todoroki Y, Ohigashi H (2000) Biosynthesis of abscisic acid by the non-mevalonate pathway in plants, and by the mevalonate pathway in fungi. Biosci Biotechnol Biochem 64:1448-1458. https://doi.org/10.1271/bbb.64.1448

Hönig M, Plíhalová L, Husičková A, Nisler J, Doležal K (2018) Role of cytokinins in senescence, antioxidant defence and photosynthesis. Int J Mol Sci 19:4045. https://doi.org/10.3390/ijms19124045

Hutner SH (1953) Comparative physiology of heterotrophic growth in plants. In: Loomis WE (ed) Growth and differentiation in plants. Iowa State College Press, Ames, IA, pp 417-446

Janeczko A (2019) Brassinosteroids in cereals-presence, physiological activity and practical aspects. In: Hayat S, Yusuf M, Bhardwaj R, Bajguz A (eds) Brassinosteroids: plant growth and development. Springer, Singapore, pp 59-88. https://doi. org/10.1007/978-981-13-6058-9_3

Kanwar MK, Bajguz A, Zhou J, Bhardwaj R (2017) Analysis of brassinosteroids in plants. J Plant Growth Regul 36:1002-1030. https:// doi.org/10.1007/s00344-017-9732-4

Kasahara H, Hanada A, Kuzuyama T, Takagi M, Kamiya Y, Yamaguchi S (2002) Contribution of the mevalonate and methylerythritol phosphate pathways to the biosynthesis of gibberellins in Arabidopsis. J Biol Chem 277:45188-45194. https://doi.org/10.1074/ jbc.M208659200

Khan A, Bilal S, Khan AL, Imran M, Al-Harrasi A, Al-Rawahi A, Lee I-J (2020) Silicon-mediated alleviation of combined salinity and cadmium stress in date palm (Phoenix dactylifera L.) by regulating physio-hormonal alteration. Ecotox Environ Saf 188:109885. https://doi.org/10.1016/j.ecoenv.2019.109885

Khvatkov P, Firsov A, Shvedova A, Shaloiko L, Kozlov O, Chernobrovkina M, Pushin A, Tarasenko I, Chaban I, Dolgov S (2018) Development of Wolffia arrhiza as a producer for recombinant human granulocyte colony-stimulating factor. Front Chem 6:304304. https://doi.org/10.3389/fchem.2018.00304

Kieber JJ, Schaller GE (2014) Cytokinins. Arabidopsis Book 12:e0168. https://doi.org/10.1199/tab.0168

Ku Y-S, Sintaha M, Cheung M-Y, Lam H-M (2018) Plant hormone signaling crosstalks between biotic and abiotic stress responses. Int J Mol Sci 19:3206

Kuhn M, Jackson S, Cimentada J (2020) corrr: correlations in R (R package version 0.4.1). https://CRAN.R-project.org/packa ge $=$ corrr. Accessed 20 Feb 2020 
Kurepa J, Shull TE, Smalle JA (2018) Cytokinin-induced growth in the duckweeds Lemna gibba and Spirodela polyrhiza. Plant Growth Regul 86:477-486. https://doi.org/10.1007/s10725-018-0446-9

Les DH, Landolt E, Crawford DJ (1997) Systematics of the Lemnaceae (duckweeds): inferences from micromolecular and morphological data. Plant Syst Evol 204:161-177. https://doi.org/10.1007/ bf00989203

Les DH, Crawford DJ, Landolt E, Gabel JD, Kimball RT (2002) Phylogeny and systematics of Lemnaceae, the duckweed family. Syst Bot 27:221-240. https://doi.org/10.1043/0363-6445-27.2.221

Li J, Wu Y, Xie Q, Gong Z (2017) Abscisic acid. In: Li J, Li C, Smith SM (eds) Hormone metabolism and signaling in plants. Academic Press, London, pp 161-202. https://doi.org/10.1016/B978-0-12811562-6.00005-0

Li YX, Deng T, Duan CF, Ni LX, Wang N, Guan YF (2019) Dispersive matrix solid-phase extraction method coupled with high performance liquid chromatography-tandem mass spectrometry for ultrasensitive quantification of endogenous brassinosteroids in minute plants and its application for geographical distribution study. J Agric Food Chem 67:3037-3045. https://doi.org/10.1021/ acs.jafc. 8 b07224

Liu H, Zhang C, Wang J, Zhou C, Feng H, Mahajan MD, Han X (2017) Influence and interaction of iron and cadmium on photosynthesis and antioxidative enzymes in two rice cultivars. Chemosphere 171:240-247. https://doi.org/10.1016/j.chemosphere.2016.12.081

Lu Y, Xu J (2015) Phytohormones in microalgae: a new opportunity for microalgal biotechnology? Trends Plant Sci 20:273-282. https ://doi.org/10.1016/j.tplants.2015.01.006

Luo XT, Cai BD, Chen X, Feng YQ (2017) Improved methodology for analysis of multiple phytohormones using sequential magnetic solid-phase extraction coupled with liquid chromatography-tandem mass spectrometry. Anal Chim Acta 983:112-120. https:// doi.org/10.1016/j.aca.2017.06.019

MacMillan J (2001) Occurrence of gibberellins in vascular plants, fungi, and bacteria. J Plant Growth Regul 20:387-442. https:// doi.org/10.1007/s003440010038

Magnone M, Bruzzone S, Guida L, Damonte G, Millo E, Scarfi S, Usai C, Sturla L, Palombo D, De Flora A, Zocchi E (2009) Abscisic acid released by human monocytes activates monocytes and vascular smooth muscle cell responses involved in atherogenesis. $\mathrm{J}$ Biol Chem 284:17808-17818. https://doi.org/10.1074/jbc.M8095 46200

Maršálek B, Šimek M (1992) Abscisic acid and its synthetic analog in relation to growth and nitrogenase activity of Azotobacter chroococcum and Nostoc muscorum. Folia Microbiol 37:159-160. https ://doi.org/10.1007/bf02836623

Murai N (2014) Review: plant growth hormone cytokinins control the crop seed yield. Am J Plant Sci 5:2178-2187. https://doi. org/10.4236/ajps.2014.514231

Ohnishi T (2018) Recent advances in brassinosteroid biosynthetic pathway: insight into novel brassinosteroid shortcut pathway. J Pestic Sci 43:159-167. https://doi.org/10.1584/jpestics.D18-040

Olds CL, Glennon EKK, Luckhart S (2018) Abscisic acid: new perspectives on an ancient universal stress signaling molecule. Microbes Infect 20:484-492. https://doi.org/10.1016/j.micin f.2018.01.009

Pan XQ, Wang XM (2009) Profiling of plant hormones by mass spectrometry. J Chromatogr B 877:2806-2813. https://doi. org/10.1016/j.jchromb.2009.04.024

Pan X, Welti R, Wang X (2010) Quantitative analysis of major plant hormones in crude plant extracts by high-performance liquid chromatography-mass spectrometry. Nat Protoc 5:986-992. https://doi. org/10.1038/nprot.2010.37

Pieterse AH (1974) Gibberellin-EDDHA interaction in flowering and gibbosity of Lemna gibba G3. Plant Cell Physiol 15:1125-1127. https://doi.org/10.1093/oxfordjournals.pcp.a075098
Piotrowska A, Bajguz A (2012) Biology of aquatic plant Wolffia arrhiza (Lemnaceae) and its practical application. In: Sridhar KR (ed) Aquatic plants and plant diseases types, characteristics and management. Nova Science Publishers Inc., Hauppauge, pp $87-116$

Piotrowska A, Bajguz A, Godlewska-Zylkiewicz B, Zambrzycka E (2010) Changes in growth, biochemical components, and antioxidant activity in aquatic plant Wolffia arrhiza (Lemnaceae) exposed to cadmium and lead. Arch Environ Contam Toxicol 58:594-604. https://doi.org/10.1007/s00244-009-9408-6

R Core Team (2019) R: a language and environment for statistical computing ( $\mathrm{R}$ version 3.6.1, Action of the Toes). R Foundation for Statistical Computing. https://www.R-project.org/. Accessed 5 July 2019

Roh J, Yeom HS, Jang H, Kim S, Youn JH, Kim SK (2017) Identification and biosynthesis of $\mathrm{C}-24$ ethylidene brassinosteroids in Arabidopsis thaliana. J Plant Biol 60:533-538. https://doi. org/10.1007/s12374-017-0132-x

Rozhon W, Akter S, Fernandez A, Poppenberger B (2019) Inhibitors of brassinosteroid biosynthesis and signal transduction. Molecules 24:4372

Samardakiewicz S, Woźny A (2000) The distribution of lead in duckweed (Lemna minor L.) root tip. Plant Soil 226:107-111. https:// doi.org/10.1023/a:1026440730839

Schäfer M, Brütting C, Meza-Canales ID, Großkinsky DK, Vankova R, Baldwin IT, Meldau S (2015) The role of cis-zeatin-type cytokinins in plant growth regulation and mediating responses to environmental interactions. J Exp Bot 66:4873-4884. https://doi. org/10.1093/jxb/erv214

Schmitz U, Kelm H (2017) First discovery of flowering Wolffia arrhiza in Central Europe. Aquat Bot 143:33-35. https://doi. org/10.1016/j.aquabot.2017.09.001

Šimura J, Antoniadi I, Široká J, Tarkowská D, Strnad M, Ljung K, Novák O (2018) Plant hormonomics: multiple phytohormone profiling by targeted metabolomics. Plant Physiol 177:476-489. https ://doi.org/10.1104/pp.18.00293

Skillicorn P, Spira W, Journey W (1993) Duckweed aquaculture: a new aquatic farming system for developing countries. World Bank, Washington, D.C.

Smith SM, Li C, Li J (2017) Hormone function in plants. In: Li J, Li C, Smith SM (eds) Hormone metabolism and signaling in plants. Academic Press, London, pp 1-38. https://doi.org/10.1016/B9780-12-811562-6.00001-3

Soda S, Kawahata Y, Takai Y, Mishima D, Fujita M, Ike M (2013) Kinetics of nutrient removal and biomass production by duckweed Wolffia arrhiza in continuous-flow mesocosms. Ecol Eng 57:210-215. https://doi.org/10.1016/j.ecoleng.2013.04.023

Sosnowski J, Malinowska E, Jankowski K, Król J, Redzik P (2019) An estimation of the effects of synthetic auxin and cytokinin and the time of their application on some morphological and physiological characteristics of Medicago x varia T. Martyn. Saudi J Biol Sci 26:66-73. https://doi.org/10.1016/j.sjbs.2016.12.023

Sree KS, Bog M, Appenroth KJ (2016) Taxonomy of duckweeds (Lemnaceae), potential new crop plants. Emir J Food Agric 28:291302. https://doi.org/10.9755/ejfa.2016-01-038

Stirk WA, van Staden J (2003) Occurrence of cytokinin-like compounds in two aquatic ferns and their exudates. Environ Exp Bot 49:77-85. https://doi.org/10.1016/S0098-8472(02)00061-8

Stirk WA, Balint P, Tarkowska D, Novak O, Strnad M, Ordog V, van Staden J (2013a) Hormone profiles in microalgae: gibberellins and brassinosteroids. Plant Physiol Biochem 70:348-353. https://doi. org/10.1016/j.plaphy.2013.05.037

Stirk WA, Ordog V, Novak O, Rolcik J, Strnad M, Balint P, van Staden $\mathrm{J}$ (2013b) Auxin and cytokinin relationships in 24 microalgal strains. J Phycol 49:459-467. https://doi.org/10.1111/jpy.12061 
Sturla L, Fresia C, Guida L, Bruzzone S, Scarfi S, Usai C, Fruscione F, Magnone M, Millo E, Basile G, Grozio A, Jacchetti E, Allegretti M, De Flora A, Zocchi E (2009) LANCL2 is necessary for abscisic acid binding and signaling in human granulocytes and in rat insulinoma cells. J Biol Chem 284:28045-28057. https://doi. org/10.1074/jbc.M109.035329

Sytar O, Kumari P, Yadav S, Brestic M, Rastogi A (2019) Phytohormone priming: regulator for heavy metal stress in plants. $\mathrm{J}$ Plant Growth Regul 38:739-752. https://doi.org/10.1007/s0034 4-018-9886-8

Tarkowska D, Strnad M (2018) Isoprenoid-derived plant signaling molecules: biosynthesis and biological importance. Planta 247:10511066. https://doi.org/10.1007/s00425-018-2878-x

Tarkowská D, Novák O, Oklestkova J, Strnad M (2016) The determination of 22 natural brassinosteroids in a minute sample of plant tissue by UHPLC-ESI-MS/MS. Anal Bioanal Chem 408:67996812. https://doi.org/10.1007/s00216-016-9807-2

Verhoef N, Yokota T, Shibata K, de Boer GJ, Gerats T, Vandenbussche M, Koes R, Souer E (2013) Brassinosteroid biosynthesis and signalling in Petunia hybrida. J Exp Bot 64:2435-2448. https://doi. org/10.1093/jxb/ert102

Verma V, Ravindran P, Kumar PP (2016) Plant hormone-mediated regulation of stress responses. BMC Plant Biol 16:86. https://doi. org/10.1186/s12870-016-0771-y

Vermaat JE, Hanif MK (1998) Performance of common duckweed species (Lemnaceae) and the waterfern Azolla filiculoides on different types of waste water. Water Res 32:2569-2576. https://doi. org/10.1016/S0043-1354(98)00037-2

Wang H, Wei Z, Li J, Wang X (2017) Brassinosteroids. In: Li J, Li C, Smith SM (eds) Hormone metabolism and signaling in plants. Academic Press, London, pp 291-326. https://doi.org/10.1016/ B978-0-12-811562-6.00009-8

Wei T, Simko V (2017) R package "corrplot": visualization of a correlation matrix (version 0.84). https://cran.r-project.org/web/packa ges/corrplot/. Accessed 17 Oct 2017
Weyers JDB, Paterson NW (2001) Plant hormones and the control of physiological processes. New Phytol 152:375-407. https://doi. org/10.1046/j.0028-646X.2001.00281.x

Xin PY, Yan JJ, Fan JS, Chu JF, Yan CY (2013) An improved simplified high-sensitivity quantification method for determining brassinosteroids in different tissues of rice and Arabidopsis. Plant Physiol 162:2056-2066. https://doi.org/10.1104/pp.113.221952

Yokota T, Ohnishi T, Shibata K, Asahina M, Nomura T, Fujita T, Ishizaki K, Kohchi T (2017) Occurrence of brassinosteroids in non-flowering land plants, liverwort, moss, lycophyte and fern. Phytochemistry 136:46-55. https://doi.org/10.1016/j.phyto chem.2016.12.020

Zhou M, Ghnaya T, Dailly H, Cui G, Vanpee B, Han R, Lutts S (2019) The cytokinin trans-zeatine riboside increased resistance to heavy metals in the halophyte plant species Kosteletzkya pentacarpos in the absence but not in the presence of $\mathrm{NaCl}$. Chemosphere 233:954-965. https://doi.org/10.1016/j.chemosphere.2019.06.023

Zocchi E, Carpaneto A, Cerrano C, Bavestrello G, Giovine M, Bruzzone S, Guida L, Franco L, Usai C (2001) The temperaturesignaling cascade in sponges involves a heat-gated cation channel, abscisic acid, and cyclic ADP-ribose. Proc Natl Acad Sci USA 98:14859-14864. https://doi.org/10.1073/pnas.261448698

Zullo MAT, Bajguz A (2019) The brassinosteroids family-structural diversity of natural compounds and their precursors. In: Hayat S, Yusuf M, Bhardwaj R, Bajguz A (eds) Brassinosteroids: plant growth and development. Springer, Singapore, pp 1-44. https:// doi.org/10.1007/978-981-13-6058-9_1

Publisher's Note Springer Nature remains neutral with regard to jurisdictional claims in published maps and institutional affiliations. 